\title{
Optimization of Short-term Overproduction Response of Variable Speed Wind Turbines
}

\author{
Altin, Müfit; Hansen, Anca Daniela; Barlas, Athanasios; Das, Kaushik; Sakamuri, Jayachandra N.
}

Published in:

I E E E Transactions on Sustainable Energy

Link to article, DOI:

10.1109/TSTE.2018.2810898

Publication date:

2018

Document Version

Peer reviewed version

Link back to DTU Orbit

Citation (APA):

Altin, M., Hansen, A. D., Barlas, A., Das, K., \& Sakamuri, J. N. (2018). Optimization of Short-term Overproduction Response of Variable Speed Wind Turbines. I E E E Transactions on Sustainable Energy, 9(4), 1732-1739. https://doi.org/10.1109/TSTE.2018.2810898

\section{General rights}

Copyright and moral rights for the publications made accessible in the public portal are retained by the authors and/or other copyright owners and it is a condition of accessing publications that users recognise and abide by the legal requirements associated with these rights.

- Users may download and print one copy of any publication from the public portal for the purpose of private study or research.

- You may not further distribute the material or use it for any profit-making activity or commercial gain

- You may freely distribute the URL identifying the publication in the public portal 


\title{
Optimization of Short-term Overproduction Response of Variable Speed Wind Turbines
}

\author{
Müfit Altin, Member, IEEE, Anca D. Hansen, Thanasis K. Barlas, Kaushik Das, Member, IEEE, and \\ Jayachandra N. Sakamuri, Member, IEEE
}

\begin{abstract}
Emphasis in this article is on the optimization of the shortterm overproduction response of variable speed wind turbines for synthetic inertia provision or fast frequency control. The short-term overproduction response of wind turbines plays a crucial role in the enhancement of the resilience of future power systems with low inertia especially during large frequency disturbances. Novel optimization approaches employing the genetic algorithm are proposed to maximize the released energy from the wind turbine during its overproduction period considering the electrical and mechanical constraints. Based on the optimization results, the article identifies and analyses a set of relevant aspects to be taken into account by power system operators and wind turbine developers in the process of designing the synthetic inertia provision or the fast frequency control. Additionally, the impact of the short-term over production response on the wind turbine structural loading is analyzed through a set of aeroelastic simulations to further investigate aerodynamic limitations.
\end{abstract}

Index Terms - wind energy integration, heuristic optimization, wind energy, power generation control, short-term overproduction, genetic algorithm, inertial response.

\section{INTRODUCTION}

$\mathrm{T}$ HE installed wind power over the world in 2016 had the capability of suppling approximately $4.7 \%$ of the global electricity demand [1]. Accordingly, in order to reduce the greenhouse gas emissions, the wind power is expected to be capable of producing $50 \%$ of Europe's electricity demand by 2050 through the green energy policies, technology improvements, and infrastructure investments [2]. Due to this sustainable increase of wind power, the fossil-fueled power plants and nuclear power plants are planned to be shut down [3]. This aspect raises serious concerns regarding the stability and security of supply of future power systems with high levels of wind power.

In order to sustain the stable operation of power systems, the grid code requirements and ancillary services are elaborated worldwide for wind power plants (WPPs) and wind turbines (WTs) [4]. These requirements and services in general are similar to those typically provided by the conventional power plants (CPPs). Accordingly, some of these

This work was supported in part by the Energinet.dk under the PSO project RePlan no. 12347.

M. Altin, A. D. Hansen, T. K. Barlas, and K. Das are with the Departmen of Wind Energy, Technical University of Denmark (DTU), Roskilde, 4000 Denmark (e-mail: mfal@dtu.dk, anca@dtu.dk, tkba@dtu.dk, kdas@dtu.dk).

J. N. Sakamuri is with ABB HVDC Ludviga, Sweden (e-mail: jaicogz@gmail.com). requirements are designed not to destabilize the power system to where WPPs are connected. However, the planned gradual displacement of CPPs due to the increasing wind penetration levels might require new services or requirements which imply important considerations for the frequency stability of power systems. Beside that fact, power systems get closer to their stability margin, and their inertia is drastically reduced unless specific control actions are considered. In this respect, recent studies have shown that there is a need for detailed specifications of the control actions from WPPs for the frequency stability [5], [6]. The focus in these studies is mainly on the assessment of the short-term response of WTs by the fast frequency control [6], also referred as synthetic inertia [7]. For the short-term overproduction response, there is no standard definition in the literature. In this study, shortterm overproduction response represents a temporary shortterm (i.e. duration less than $30 \mathrm{sec}$.) active power increase which can be specified by a predefined step, synthetic inertia, or fast frequency control.

The state-of-the-art shows that modern WTs [8] are not capable of providing a short-term response without any control effort following a grid frequency event. The displacement of nuclear and coal-fired thermal power plants in accordance, while installing more and more WPPs can create critical operational scenarios where the power system inertia is reduced both for islanded [9], [10] (e.g. Ireland, UK) and interconnected power systems [11]. In future power systems with high penetration of wind power, the low system inertia may cause frequency instability and lead to load shedding or generation disconnections [6]. In order to overcome these challenges, WPPs can be utilized to provide a short-term support such as fast and temporary frequency support through proper controllers which comprehend frequency measurement and event detection functionalities [6], [12]. Two types of control methods are proposed so far, namely one which enables a reserve power by down-regulating WTs [13] and another one which provides additional power by operating the WTs in overproduction mode [14]. In the first controller type, the reserve power is kept by activating the pitch controller or operating above the rated rotational speed to provide the required amount of the power during the frequency disturbance. However, in the second controller type, the shortterm overproduction response without any reserve allocation is released from the kinetic energy of the WT. Several studies regarding the inertial response contribution [14]-[19] have shown that at wind speeds below rated, the short-term overproduction period is followed by an underproduction 
(recovery) period, which can be characterized by a power drop below the pre-event value. This underproduction can be considerable especially at wind speeds below rated wind, depending on the adopted control strategy, as depicted in [12]. There are challenges in order to provide the short-term overproduction response of WPPs regarding the released energy and the underproduction period. Therefore, this article targets analyzing the optimization of the short-term overproduction response of variable speed wind turbines (VSWTs) with special focus on wind speeds below rated.

Several studies have investigated the short-term overproduction response in order to analyze the capability of VSWTs to support the frequency stability of power systems [15]-[19]. In [15] and [16], the focus is on the relationship between the released energy, rotational speed and electrical torque of the WT while performing sensitivity analysis by varying some key parameters such as the magnitude of the applied power and the duration of the overproduction. Some of the mechanical and electrical limitations of the WTs are considered in these studies. In [17], a heuristic optimization approach, namely the genetic algorithm, is used to tune the parameters of the inertial response from all WPPs as an aggregated response into the power system. However, in this study the dynamics of the VSWT are not taken specifically into account due to the system level approach with focus on the geographically distributed WPPs. Furthermore in [18], the convex optimization method is applied to maximize the duration of the pre-defined additional power. In [18], similar to [17] the VSWT dynamics are not represented in detail and the predefined power reference value is a fixed value which is independent of the frequency deviations obtained from a power system. Finally, in [19] the shape of the additional power during a frequency deviation is optimized using the particle swarm optimization method. The study considers the frequency dynamics of a power system as similar in [17] and additionally the dynamics of the VSWT similar to the [18]. However, without considering the frequency measurements such as the frequency and the rate-of-change-of-frequency (ROCOF) during the frequency deviation, the results of the tuning approach in [19] might be limited and difficult to apply for various power system operating states and wind speed conditions. Therefore, there is a need for an approach employing an optimization method in order to further investigate the short-term overproduction response of the VSWTs considering its mechanical and electrical limitations with power system frequency dynamics.

The objective of this study is to analyze and quantify the short-term overproduction response of VSWTs by maximizing the released energy with consideration of the mechanical and electrical limitations and the frequency dynamics of a power system. The genetic algorithm is employed as the optimization method in three approaches. In the first approach, the duration of the overproduction period is optimized for different predefined active power setpoints of the WT. The second approach includes both the active power setpoint and the duration of the response in the optimization algorithm as two decision variables. Furthermore, in the third approach instead of keeping the active power setpoint as a constant value, the optimization study is performed based on the measurements of the frequency deviation and the ROCOF for a benchmark power system. Finally, the contribution of the study is further extended by analyzing the impact of the overproduction response on the loading of the WT structural components. This impact analysis has not been considered in the previous studies.

The article is organized as follows. Section II briefly describes the simplified WT model which is based on extended IEC standard model. In Section III, the optimization of short-term overproduction capability is presented for various wind speeds below rated wind speed in three aforementioned approaches. The impact of the short-term overproduction on the WT loading is analyzed from an aeroelastic simulation perspective in Section IV. Finally, conclusive remarks are reported in Section V, where the track for future work regarding the short-term overproduction of WTs is also suggested.

\section{SimPlified WIND TURBINE MODEL FOR OPTIMIZATION STUDIES}

The common practice regarding the modelling of WTs is to represent the response of the WT with a required level of accuracy and details relevant for power system integration studies. Generic models of WTs and WPPs have been developed recently in the IEC 61400-27 standard [8], [20], [21], having an aim to represent the WT's behavior for shortterm voltage stability studies. As these models do not include wind speed variability and WTs' aerodynamic features, they are not appropriate for frequency control studies, such as inertial response or short-term frequency support. In [22], an extended version of the IEC 61400-27 model is introduced including the wind speed variability, a simplified aerodynamic model as well as its coupling to the mechanical model, which is essential in order to account adequately for the dynamics and the limits of the rotor speed. With this extension, the model can be further used in the investigation of the shortterm overproduction response [16].

In this present article, a simplified WT model is developed based on the extended and detailed model described in [22] in order to be used with an optimization method while keeping the relevant aerodynamic and active power control performance. The detailed and simplified models are depicted in Figure 1, respectively. Notice that the reactive power control and the WPP controller related models are removed in the simplified WT model, as the focus in this work is on the active power/frequency control capability of the WT. NREL $5 \mathrm{MW}$ reference WT data is employed for aerodynamic and mechanical models [23]. The rated power of the WT is $5 \mathrm{MW}$ and the WT parameters are given in Appendix. The following assumptions are made for the simplification procedure: 

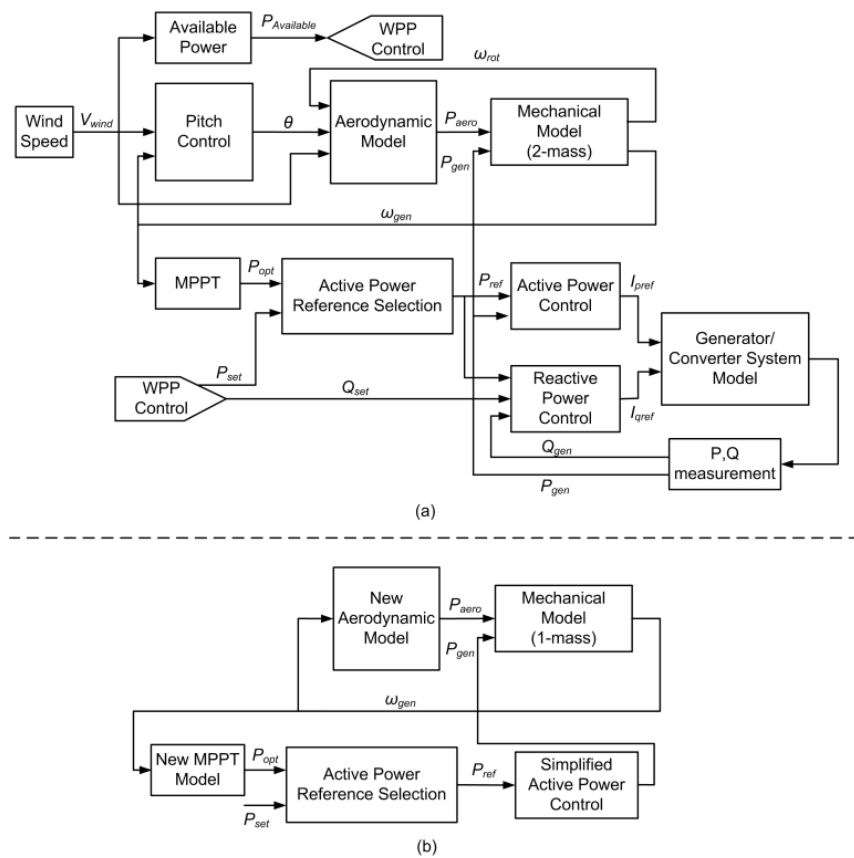

Fig. 1. Wind turbine (a) detailed [22] and (b) simplified models

- The 2-D lookup tables for the aerodynamic efficiency and the maximum power point (MPPT) table are replaced by polynomial functions as result of the MPPT curve fitting in the overproduction region, as illustrated in Figure 2a and Figure 2b, respectively.

- The 2-mass mechanical model in the detailed WT model is replaced by a single-mass model, as the stiffness and damping of the shaft are not relevant for the focus of this study.

- The pitch controller is removed in the simplified model since the focused wind speed region is below rated wind speed (i.e. where the pitch angle is kept constant to its optimal value).

- Active power control dynamics are simplified and represented as a first-order filter not to increase the computation time of the optimization algorithm.

- The wind speed is assumed constant during the overproduction period. Notice that in this study the focus is only on wind speeds below rated.

The aerodynamic model in Figure 1a, calculates the aerodynamic power of the turbine $\left(P_{\text {aero }}\right)$ using the pitch angle $(\theta)$, the tip-speed ratio $(\lambda)$ and the power coefficient $\left(C_{P}\right) . C_{P}$ is an interpolated value from the predefined 2-D lookup table to calculate $P_{\text {aero }}$ [23]. VSWTs operate at the optimum value of $C_{P}$ (peak value of the curve fitting in Figure 2a) before the overproduction response. When the overproduction is enabled, the operating point is shifted to the left due to the reduction in $\lambda$. After the overproduction period, the $C_{P}$ reaches again its optimum value by the action of the MPPT control. Therefore, the focused region for this optimization study is the left half plane of the $C_{P}$ curve in Figure 2a with respect to constant wind speed and optimal $\theta$. In the simplified model, this curve fitting for the $C_{P}$ is applied in the overproduction region of the WT and the obtained polynomial function is included in the new aerodynamic model (Figure 1b).
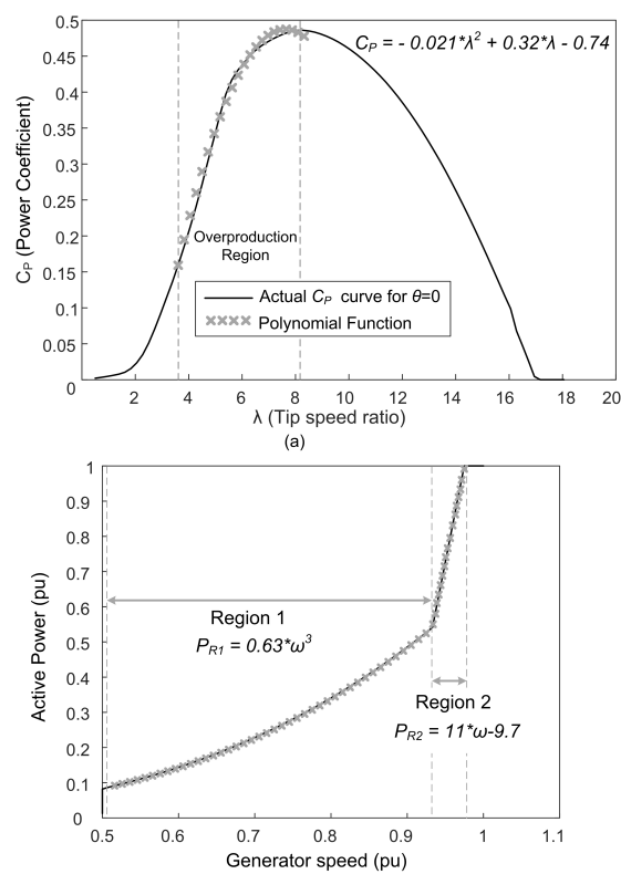

Fig. 2. (a) Curves fitting for Aerodynamic $C_{P}$ and (b) MPPT blocks used in simplified wind turbine model

All these simplifications are done in order to increase the speed of the optimization process while keeping the focus on the relevant dynamics for aerodynamic and mechanical models. The comparison between the simulation results during WT's overproduction period for the simplified and the detailed model is presented in Section IV.

\section{OptimizATION OF SHORT-TERM OVERPRODUCTION CAPABILITY}

In this section, the optimization of the short-term overproduction response of the WT using the genetic algorithm (GA) is presented. GA is well established method in the literature based on the mechanism of natural selection to constitute search and optimization procedure [25], [26]. It can produce high quality solutions because it is independent of the choice of the initial configuration of the problem. The optimal solution is sought after from a population of solutions using random process. A new generation is created by applying to the current population the three following operators: reproduction, crossover and mutation. Moreover, GA has the advantages that it can be manage nonlinearities and provide the global optimum. Since the WT model and the dynamics of the short-term overproduction response are non-linear with both continuous and discrete variables, the GA is selected in this work in order to effectively solve the optimization problem. As investigated in [18], the traditional linear optimization methods can be used by linearizing the simplified WT model, however the response of the linearized model is not accurate enough for the whole operating range of the overproduction response. Additionally, different variations of WT model and overproduction response can be easily handled with the GA. The flow chart of the GA employed in this work is presented in Figure 3. 


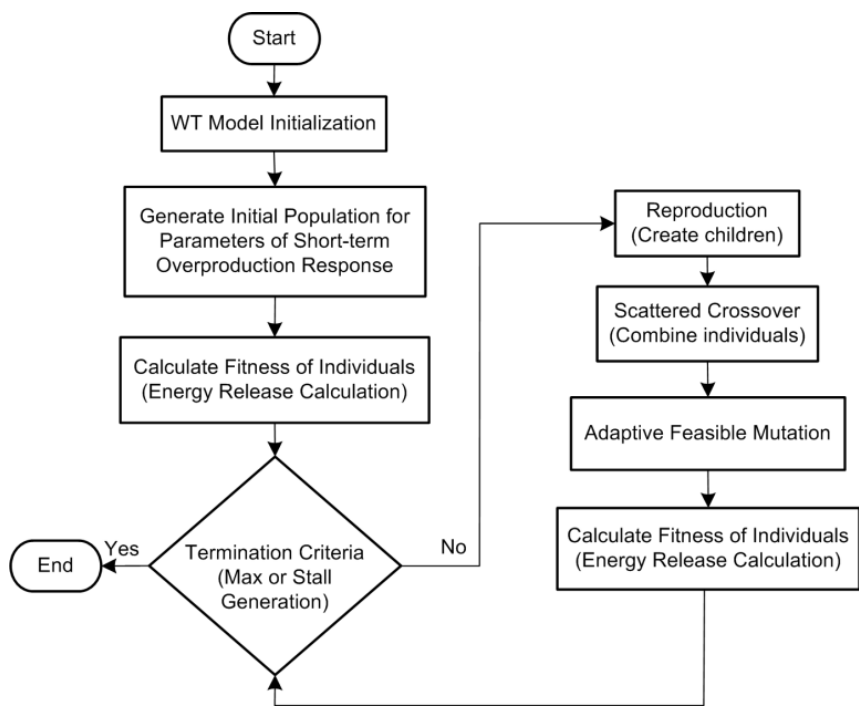

Fig. 3. Flowchart of GA for short-term overproduction response

In this work, GA is utilized to maximize the energy $\left(E_{\text {over }}\right)$ during the over-production period $\left(\Delta T_{\text {over }}\right)$. The objective function and constraints for the GA are defined as follows and the illustration of the variables is given in Figure 4:

$$
\begin{aligned}
\text { maximize } & E_{\text {over }}=\Delta P_{\text {over }}(t) . \Delta T_{\text {over }} \\
\text { subject to } & \frac{d\left(\omega_{\text {gen }}(t)\right)}{d t}=\frac{1}{2 H}\left(\frac{P_{\text {aero }}(t)-P_{\text {gen }}(t)}{\omega_{\text {gen }}(t)}\right) \\
& \frac{d\left(P_{\text {gen }}(t)\right)}{d t}=\left(P_{\text {init }}+\Delta P_{\text {over }}(t)-P_{\text {gen }}(t)\right) / T_{\text {WT }} \\
& P_{\text {aero }}(t)=-0.021\left(R \omega_{\text {gen }}(t) / V_{\text {init }}\right)^{2}+0.32 R \omega_{\text {gen }}(t) / V_{\text {init }}-0.74 \\
\omega_{\text {gen }}(t) \geq \omega_{\text {min }} & P_{\text {gen }}(t) / \omega_{\text {gen }}(t) \leq \tau_{\text {max }} \\
& \left|P_{\text {init }}-P_{\text {opt }}(t)\right| \leq 0.1\left\{\begin{array}{l}
P_{\text {opt }}(t)=0.63 \omega^{3} \quad(\text { in region } 1) \\
P_{\text {opt }}(t)=11 \omega-9.7(\text { in region } 2)
\end{array}\right. \\
& t \leq \Delta T_{\text {over }}
\end{aligned}
$$

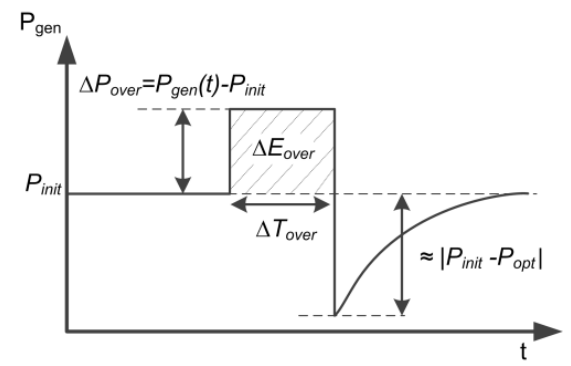

Fig. 4. Illustration of objective function and constraints

where $\Delta P_{\text {over }}$ is the additional active power during $\Delta T_{\text {over }}, \omega_{\text {gen }}$ is the generator speed as the output of the mechanical model (Figure $1 \mathrm{~b}), P_{\text {aero }}$ is the aerodynamic power as the output of the aerodynamic model (Figure 1b), $H$ is the total inertia of the WT, $R$ is the WT blade length, and $V_{\text {init }}$ is the initial wind speed. Equations from (2) to (4) describe the simplified WT model in Figure 1b. Equation (2) represents the drive train of the WT as a single mass model (Figure 1b) which describes the equation of motion. Equation (3) is for the simplified active power control, and the calculation of $P_{\text {aero }}$ is given as
Equation (4). Furthermore, Equations (5)-(7) are the mechanical and electrical limitations considering minimum generator speed $\left(\omega_{\min }\right)$, maximum generator torque $\left(\tau_{\max }\right)$, and the generation of the optimum power according to MPPT $\left(P_{\text {opt }}\right)$. Additionally, the optimum power constraint limits the drastical decrease of the active power of the WT just after the release of the overproduction in order to reduce the negative impact on the power system. Finally, $T_{W T}$ is the time constant for the active power control response of the WT.

The aforementioned parameters $H, R$, and $V_{\text {init }}$ have influence on the overproduction response of the WT. $H$ will affect directly the deceleration of the turbine. $R$ does not have large impact on the deviations of $P_{\text {aero }}$. However, $R$ influences indirectly $H$ value such that large WTs have long blades causing large turbine inertia. Finally, $V_{\text {init }}$ determines the initial operating point of the WT and thus considerably influences the overproduction response which will be seen in the optimization results.

This optimization problem is generic and can be applied to any type of WTs. Notice that the objective function can have two decision variables, i.e. additional active power $\left(\Delta P_{\text {over }}\right)$ and duration $\left(\Delta T_{\text {over }}\right)$ of the overloading. In order to solve the optimization problem by applying GA, three approaches to maximize the energy $\left(E_{\text {over }}\right)$ during the over-production period are considered as follows and the illustration of these approaches is given in Figure 5:

- Approach 1 - assumes that $\Delta P_{\text {over }}$ is predefined with respect to practical reasons (e.g. according to power system operators' requirement) and only $\Delta T_{\text {over }}$ is optimized for various $\Delta P_{\text {over }}$ values.

- Approach 2 - optimizes both $\Delta P_{\text {over }}$ and $\Delta T_{\text {over }}$ variables. In this approach, $\Delta P_{\text {over }}$, which represents the additional power on top of the initial active power value, is kept constant during $\Delta T_{\text {over }}$.

- Approach 3 - employs the frequency deviation $(\Delta f)$ and ROCOF (df/dt) as inputs to the optimization algorithm using the inertial response control described in [14]. The optimal values for $\Delta T_{\text {over }}$ and the control parameters $\left(K_{\text {in }}\right.$ and $K_{f}$ ) of this control are identified to maximize $E_{\text {over } P .} . \Delta \mathrm{f}$ and ROCOF values are defined based on the validated power system model for a real disturbance described in [24].

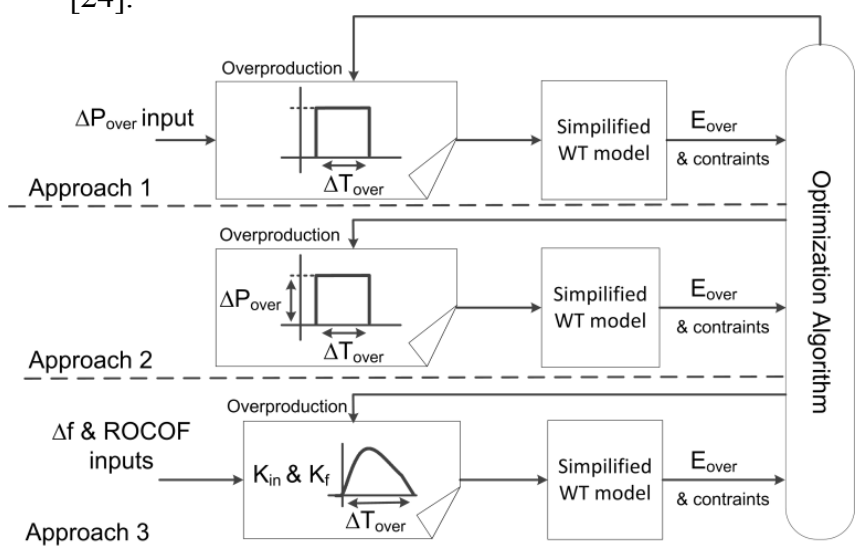

Fig. 5. Illustration of optimization approaches for short-term overproduction response of wind turbines 
The optimization results from these three approaches quantify particularly the short-term overproduction capability of the generic WT in terms of the optimized variables and the over-production profile (i.e. active power and duration) for different wind speeds.

\section{A. Optimization of $\Delta T_{\text {over }}$ with various predefined $\Delta P_{\text {over }}$}

As mentioned above, the Approach 1 maximizes $E_{\text {over }}$ by optimizing $\Delta T_{\text {over }}$ while $\Delta P_{\text {over }}$ is kept constant during the optimization at a predefined value between 0.01 to $0.3 \mathrm{pu}$ (5MW base). The optimization results (i.e. overproduction period versus power overproduction set points) are given in Figure $6 \mathrm{a}$ for different wind speeds. According to these results, it is clear that the maximum energy which can be extracted out of the WT within the defined constraints (5)-(7) is achieved for the wind speed of $7 \mathrm{~m} / \mathrm{s}$ (Figure 6b). It is also worth noticing that the pattern of the optimized results is similar in Region 1 (i.e. wind speeds from $6 \mathrm{~m} / \mathrm{s}$ to $9 \mathrm{~m} / \mathrm{s}$ ) to maximize $E_{\text {over }}$. However, close to the rated wind speed (Region 2) the drop in the optimum power is very steep due to MPPT curve (Figure 2b) and the $P_{\text {opt }}$ constraint limits $E_{\text {over }}$. This conclusion is quite interesting as one would expect to extract more energy at higher wind speeds even within the defined constraints. Accordingly, any control attempt demanding a large energy during very short overproduction duration should be designed carefully due to the high active power reduction of WTs when the overproduction is released (i.e. recovery period).

\section{B. Optimization of $\Delta T_{\text {over }}$ and $\Delta P_{\text {over }}$}

For Approach 2, both $\Delta T_{\text {over }}$ and $\Delta P_{\text {over }}$ are assumed as decision variables in the optimization algorithm. The results presented in Table 1 are consistent with the results in the Approach 1, namely the maximized energy extracted out of the WT is achieved for the wind speed of $7 \mathrm{~m} / \mathrm{s}$. Notice also that the maximized energy for the wind speed of $7 \mathrm{~m} / \mathrm{s}$ is slightly increased due to the selection of $\Delta P_{\text {over }}$ as a decision variable. Furthermore, Approach 2 shows that the maximized energy is obtained for durations less than $5 \mathrm{sec}$. If $\Delta T_{\text {over }}$ increases to obtain the same amount of energy, the constraints will be violated (i.e. longer $\Delta T_{\text {over }}$ less $E_{\text {over }}$ ) and hence an optimum solution will not be achieved.

TABLE I

\begin{tabular}{cccc} 
APPROACH 2 OPTIMIZATION RESULTS & $\left(\mathrm{P}_{\mathrm{BASE}}=5 \mathrm{MW}\right)$ \\
\hline \hline $\begin{array}{c}\text { Wind Speed } \\
(\mathrm{m} / \mathrm{s})\end{array}$ & $\begin{array}{c}\Delta P_{\text {over }} \\
(\mathrm{pu})\end{array}$ & $\begin{array}{c}\Delta T_{\text {over }} \\
(\mathrm{s})\end{array}$ & $\begin{array}{c}E_{\text {over }} \\
(\mathrm{pu} . \mathrm{s})\end{array}$ \\
\hline 10 & 0.104 & 1 & 0.10 \\
9 & 0.246 & 3 & 0.74 \\
8 & 0.287 & 3 & 0.86 \\
7 & 0.252 & 4 & 1.01 \\
6 & 0.246 & 3 & 0.74 \\
\hline
\end{tabular}
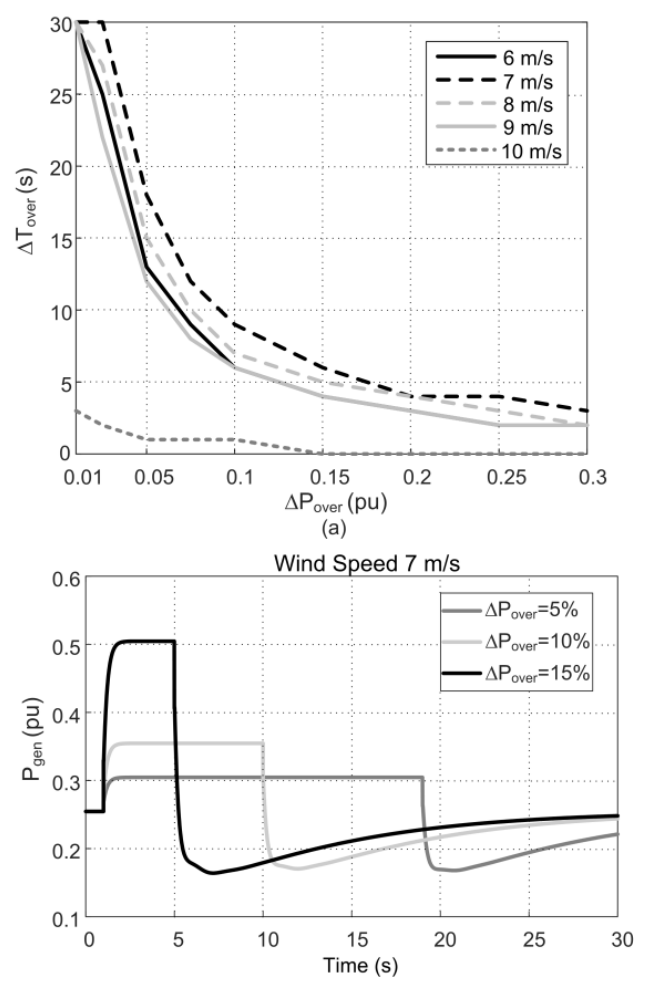

(b)

Fig. 6. (a) Optimization results of approach 1 for different wind speeds and (b) Active power output (in $5 \mathrm{MW}$ base) of wind turbine at $7 \mathrm{~m} / \mathrm{s}$

\section{Optimization of Inertial Response Parameters $K_{\text {in }}$ and $K_{f}$} with $\Delta T_{\text {over }}$

In Approach 3, the signals ( $R O C O F$ and $\triangle f$ ) which are employed in the inertial response control [14] are used as inputs to the optimization algorithm and the parameters $K_{\text {in }}$ and $K_{f}$, depicted in frequency controller in Figure 7, namely the derivative gain and the droop gain respectively are optimized. The inputs in the optimization algorithm, presented in Figure 7, are obtained from the power system model described and validated in [24].

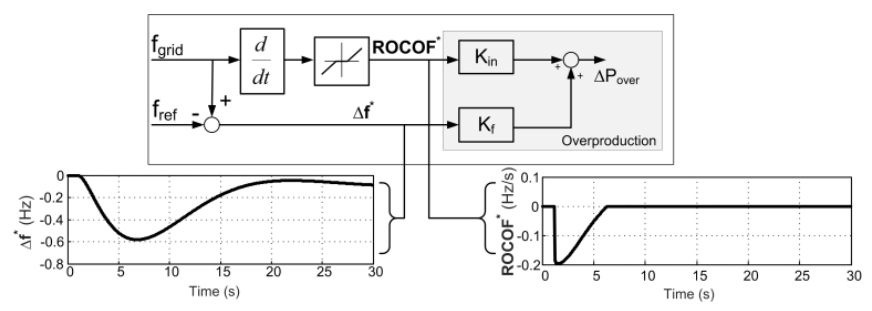

Fig. 7. Inertial Response [14] Implementation with $\Delta \mathrm{f}$ and ROCOF Signals

Based on these signals, the decision variables $\left(K_{i n}, K_{f}\right.$, and $\Delta T_{\text {over }}$ ) are optimized and the results of Approach 3 are compared with the other two approaches in Figure 8a. The optimization results in Approach 3 showed that ROCOF signal has higher impact on the optimized response than $\Delta f$ signal. Due to the high value of $R O C O F$ signal at the beginning of the frequency deviation (Figure 7), $K_{\text {in }}$ is more determinant than $K_{f}$ in the optimized response. The optimization results for the three approaches are similar, i.e. the shape of the maximum energy extracted out of the WT is similar at the different considered wind speeds. All three approaches indicate that the 
maximum energy during a short-term overproduction of a WT can be extracted at the wind speed of $7 \mathrm{~m} / \mathrm{s}$. The same results are obtained at $7 \mathrm{~m} / \mathrm{s}$ wind speed for a generic $2 \mathrm{MW}$ WT model. Therefore, it can be concluded that the medium wind speeds are optimal for the short-term overproduction independent of the size of the WT.

In Figure 8a, a comparison between the results of the Approach 1, Approach 2 and Approach 3 are shown in terms of the maximized energy $\left(E_{\text {over }}\right)$. The differences between the approaches are due to the $\Delta P_{\text {over }}$ response (i.e. a predefined value or a frequency dependent variable) and convergence tolerance of the GA. Furthermore, in Figure 8b, the simplified model used in the optimization study is verified with the detailed model at $7 \mathrm{~m} / \mathrm{s}$ wind speed. The discrepancy between the simplified and the detail models is the minimum value of the active power after the overproduction due to the simplification of mechanical model.
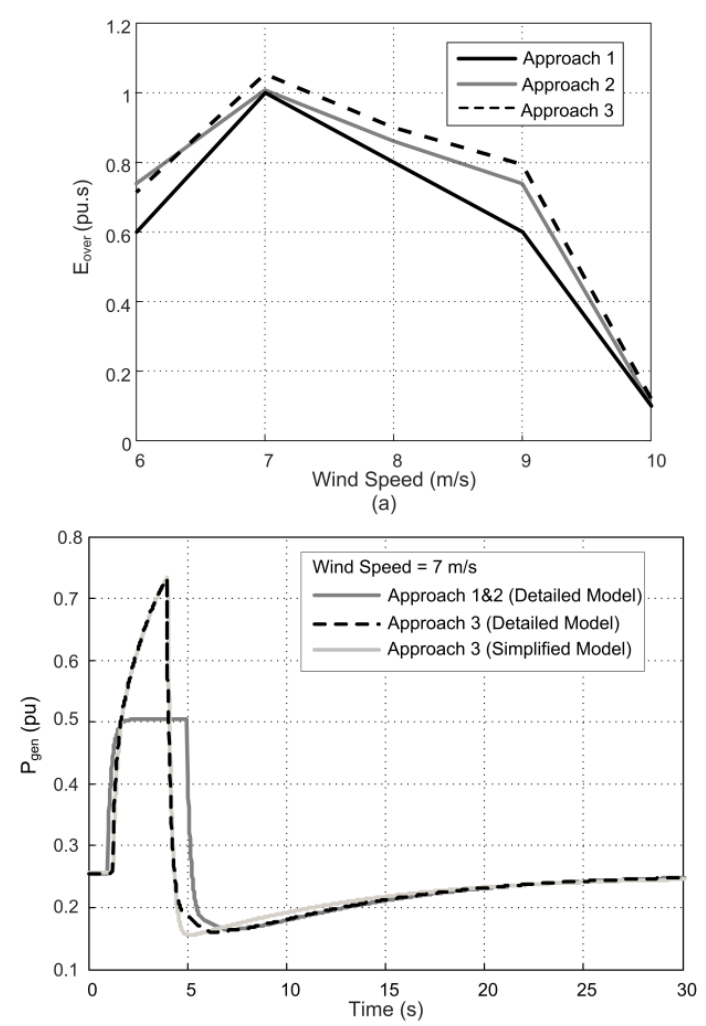

(b)

Fig. 8. (a) Optimization results of proposed approaches in terms of $E_{\text {over }}$ for different wind speeds and (b) Active power output (in 5MW base) of wind turbine at $7 \mathrm{~m} / \mathrm{s}$ for proposed approaches

\section{IMPACT OF SHORT-TERM OVERPRODUCTION ON WIND TURBINE LOADING}

The optimization study of the short-term overproduction is performed by employing the generic simplified model of the VSWT with the full scale converter. As mentioned in the modeling section, this model represents the performance of the VSWT for power system studies without considering the aeroelastic model of the WT structural components. Therefore, the aeroelastic code HAWC2 is employed in order to analyze the impact of the short-term overproduction on the structural loads. The HAWC2 (Horizontal Axis Wind turbine simulation Code $2^{\text {nd }}$ generation) is a Blade Element Momentum (BEM) based tool using a multi-body dynamics approach [27]. An open loop simulation is performed to run the HAWC2 and to obtain the loading of the structural components. For the open loop simulations, the baseline power controller in HAWC2 [28] is bypassed and the prescribed generator torque profile in time series is introduced as an input to the HAWC2 code in order to obtain different overproduction power $\left(\Delta P_{\text {over }}=2.5 \%\right.$, $10 \%$, and $30 \%$ of available power) for different overproduction periods $\left(\Delta T_{\text {over }}=30 \mathrm{~s}, 9 \mathrm{~s}\right.$, and $\left.4 \mathrm{~s}\right)$, respectively. These three cases have been simulated as the open loop for a constant wind speed of $7 \mathrm{~m} / \mathrm{s}$. The results of the impact analysis are shown in Figure 9a in terms of active power performance and the calculated ultimate loads in Figure $9 \mathrm{~b}$. Under the constant wind speed, especially the $30 \%$ overproduction case results in considerable increases in tower, yaw bearing, and main bearing bending moments, mainly in the side-side/roll directions.

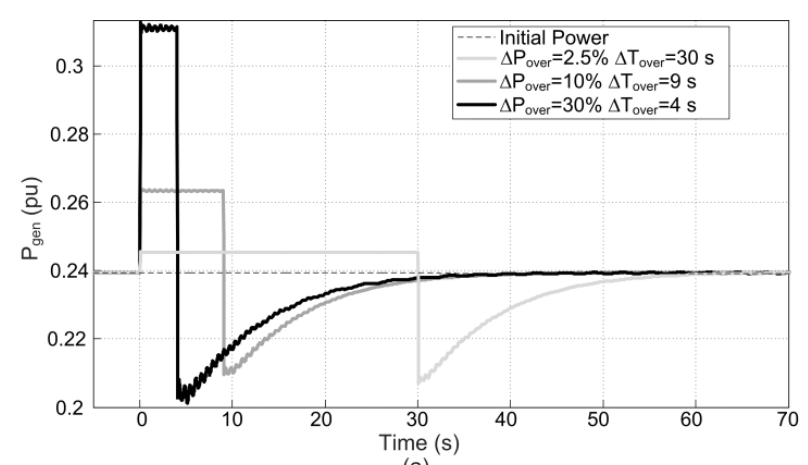

(a)

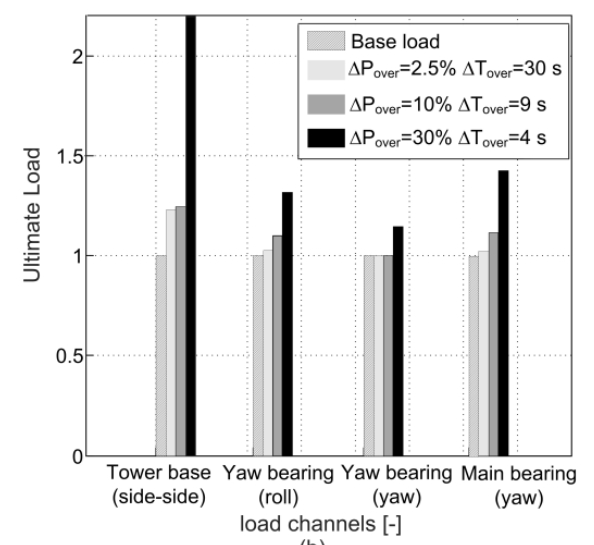

(b)

Fig. 9. (a) Active power output (in 5MW base) of wind turbine for different overproduction setpoints and (b) Ultimate load (i.e. base loading as 1) comparison of these cases at $7 \mathrm{~m} / \mathrm{s}$

The loading results show that the active ramp down rate should be limited not to increase the stress at the tower base and the yaw. Furthermore, the amount of the active power overproduction and its duration should be considered with the ramp-down rate of this active power response. This limitation can be included in the optimization algorithm as a new constraint and in the active power control loop of the detailed VSWT model as an extension of this work. 


\section{CONCLUSION}

In this article, optimization of the short-term overproduction response of variable speed wind turbines considering electrical and mechanical constraints is described and investigated in detail. The released energy during the overproduction response is maximized using the genetic algorithm with special focus on wind speeds below rated value. Accordingly, different optimization approaches are introduced by investigating the overproduction profile based on either the duration and the overproduction power setpoint or the inertial response parameters related to the frequency deviation and the rate-of-change-of-frequency. The proposed approaches are showing consistent results in terms of the maximized energy. Furthermore, the impact of the short-term overproduction on the wind turbine loading is analyzed through a set of open loop aerolastic simulations.

The results have shown that the maximum energy can be extracted depending on the overproduction power setpoint, the duration of the overproduction, and the operating conditions of the wind turbine for different wind speeds. Additionally, it is seen that for different wind turbine sizes, the optimum energy is released around the same wind speed region. Looking at the impact of the short-term overproduction on the wind turbine loading, it has been seen that the ramp down rate of the active power after the overproduction is crucial for the structural loading.

This work can be used as a starting point in the design of the synthetic inertia provision or the fast frequency control from variable speed wind turbines for power system operators and wind turbine developers.

\section{APPENDIX}

TABLE II

\begin{tabular}{cc} 
NREL 5MW WIND TURBINE PARAMETERS [23] \\
\hline Rating & 5MW \\
\hline Control & Variable Speed \\
\hline Rotor Diameter & $126 \mathrm{~m}$ \\
\hline Cut-In, & $3 \mathrm{~m} / \mathrm{s}$, \\
Rated, & $11.4 \mathrm{~m} / \mathrm{s}$, \\
Cut-Out Wind Speed & $25 \mathrm{~m} / \mathrm{s}$ \\
\hline Rated Tip Speed & $80 \mathrm{~m} / \mathrm{s}$ \\
\hline Rotor Inertia & $35444067 \mathrm{~kg} . \mathrm{m}^{2}$ \\
\hline Generator Inertia & $534 \mathrm{~kg} . \mathrm{m}^{2}$ \\
\hline Gear Ratio & 97
\end{tabular}

\section{ACKNOWLEDGMENT}

Energinet.dk is acknowledged for funding this work in contract number: PSO project 2015 no. 12347: "Ancillary services from renewable power plants (RePlan)", www.replanproject.dk.

\section{REFERENCES}

[1] World Wind Energy Association (WWEA), "WWEA Half-Year Report," Oct. 2016.

[2] European Wind Energy Association (EWEA), "2050: Facilitating 50\% Wind Energy - Recommendations on transmission infrastructure, system operation and electricity market integration,' http://bit.ly/2hOVgh8, 2011.

[3] ENTSO-E, "Ten-Year Network Development Plan 2014," http://bit.ly/2h97hdu, 2014.
[4] M. Altin, O. Goksu, R. Teodorescu, P. Rodriguez, B. Bak-Jensen, L. Helle, "Overview of recent grid codes for wind power integration", Proc. OPTIM, 2010, pp. 1152-1160.

[5] VTT, IEA Wind Task 25, "Design and Operation of Power Systems with large amounts of Wind Power, Final summary report," 2016.

[6] European Wind Energy Association (EWEA), "Economic Grid Support Services by Wind and Solar PV - A review of system needs, technology options, economic benefits and suitable market mechanisms," REserviceS project, 2014

[7] European Network of Transmission System Operators for Electricity (ENTSO-E), "Network Code on Requirements for Grid Connection Applicable to all Generators (RfG),"2016, http://bit.ly/2ipA3e2.

[8] International Electrotechnical Commission (IEC), "Electrical simulation models - Wind turbines, IEC Standard 61400-27-1", Feb. 2015.

[9] J. O'Sullivan, A. Rogers, D. Flynn, P. Smith, A. Mullane and M. O'Malley, "Studying the Maximum Instantaneous Non-Synchronous Generation in an Island System-Frequency Stability Challenges in Ireland," in IEEE Transactions on Power Systems, vol. 29, no. 6, pp. 2943-2951, Nov. 2014.

[10] National Grid, "System Operability Framework (SOF), UK Electricity Transmission," 2015, http://ngrid.com/2hRr0Su.

[11] ENTSOE RG-CE System Protection and Dynamics Sub Group, "Frequency Stability Evaluation Criteria for the Synchronous Zone of Continental Europe," 2016, http://bit.ly/2j8fQuo.

[12] M. Dreidy, H. Mokhlis, and S. Mekhilef,"Inertia response and frequency control techniques for renewable energy sources: A review." Renewable and Sustainable Energy Reviews, pp. 144-155, 2017.

[13] R. G. de Almeida and J. A. P. Lopes, "Participation of Doubly Fed Induction Wind Generators in System Frequency Regulation," in IEEE Transactions on Power Systems, vol. 22, no. 3, pp. 944-950, Aug. 2007.

[14] J. Morren, S. W. H. de Haan, W. L. Kling and J. A. Ferreira, "Wind turbines emulating inertia and supporting primary frequency control," in IEEE Transactions on Power Systems, vol. 21, no. 1, pp. 433-434, Feb. 2006.

[15] G. C. Tarnowski, "Coordinated frequency control of wind turbines in power systems with high wind power penetration", Ph.D. dissertation, Dept. Elect. Eng., Technical University of Denmark, Nov. 2011.

[16] A. D. Hansen, M. Altin, I. D. Margaris, F. Iov, and G. C. Tarnowski, 2014. "Analysis of the short-term overproduction capability of variable speed wind turbines," Renewable Energy, vol. 68, pp.326-336, Aug. 2014.

[17] L. Ruttledge and D. Flynn, "Emulated Inertial Response from Wind Turbines: Gain Scheduling and Resource Coordination", in IEEE Transactions on Power Systems, vol. 31, no. 5, pp. 3747-3755, Sept. 2016

[18] M. Juelsgaard, J. Bendtsen and R. Wisniewski, "Utilization of Wind Turbines for Upregulation of Power Grids," in IEEE Transactions on Industrial Electronics, vol. 60, no. 7, pp. 2851-2863, July 2013.

[19] F. Hafiz, and A. Abdennour, "Optimal use of kinetic energy for the inertial support from variable speed wind turbines," Renewable Energy, vol. 80, pp. 629-643, Dec. 2015.

[20] Western Electricity Coordinating Council, "WECC wind power plant dynamic modeling guide," April 2014.

[21] NERC Special Report, "Standard Models for Variable Generation," May 2010.

[22] Anca D. Hansen, Ioannis D. Margaris, German C. Tarnowski, Florin Iov, "Simplified Type 4 wind turbine modeling for future ancillary services," European Wind Energy Conference and Exhibition (EWEC), Vol. 2 p. 768-774, 2013.

[23] J. Jonkman, S. Butterfield, W. Musial, and G. Scott, "Definition of a 5MW reference wind turbine for offshore system development," NREL, Golden, Colorado, NREL/TP-500-38060, February 2009.

[24] ENTSO-E Nordic Analysis Group, "Future System Inertia Report," 2013. https://www.entsoe.eu/Documents/Publications/SOC/Nordic/ Nordic_report_Future_System_Inertia.pdf.

[25] K. Y. Lee, M. A. El-Sharkawi, Modern Heuristic Optimization Techniques with Applications to Power Systems, IEEE Power Engineering Society (02TP160), 2002.

[26] K. Deb, Optimization for engineering design: Algorithms and examples, PHI Learning Pvt. Ltd., 2012.

[27] T. J. Larsen et al. How 2 Hawc2, the user's manual Technical report, Risø-R-1597(ver. 4-4) (EN) 2013.

[28] DTU Wind Energy Controller, https://github.com/DTUWindEnergy/ BasicDTUController. 


\section{BIOGRAPHIES}

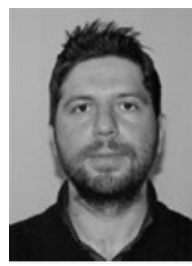

Müfit Altin - (S'09-M'13) received B.Sc. and M.Sc. degrees in electrical and electronics engineering from Middle East Technical University (METU), Ankara in 2004 and 2008, respectively. He obtained his $\mathrm{PhD}$ degree from the Dept. of Energy Technology, Aalborg University, Denmark, in 2012, where he was employed as a researcher under the Vestas Power Programme during his PhD. Since February 2013, he has been a postdoc/researcher at the Dept. of Wind Energy, Technical University of Denmark. His research interest includes grid connection of wind power, wind power plant control, power system modelling, and power system stability analysis.

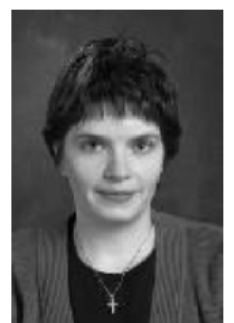

Anca D. Hansen received the degree in aerospace engineering from the Technical University of Bucharest, Romania, and a Ph.D. degree in modelling and control engineering from Denmark Technical University. She then joined Risø National Laboratory, working first as PostDoc and then as scientist. Today, she is working as senior scientist at DTU Wind Energy Dept., in Denmark. Her research interest is integration of wind power into power systems, involving topics like dynamic modelling and control of wind power plants, ancillary services as well as power system control and stability. She is author or co-author of more than 100 journal/conference papers and several research reports.

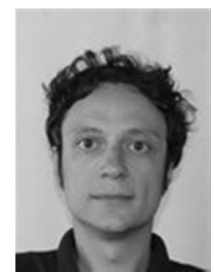

Thanasis (Athanasios) K. Barlas is a Dr. Dipl. Eng. Mechanical Engineer who has been active in wind turbine research for the past 10 years. He graduated from University of Thessaly (UTH) in Greece in 2004, acquired his PhD in Delft University of Technology in 2011 and pursued his post-doc research at DTU Wind Energy in 2011-2012. He had been a research advisor at the Laboratory of Fluid Mechanics and Turbomachinery at the Department of Mechanical Engineering in UTH in 2012-2016. He is currently a researcher at DTU Wind Energy. His main research interests include active aerodynamic control, smart blades, unsteady aerofoil and wake aerodynamics and aeroelasticity.

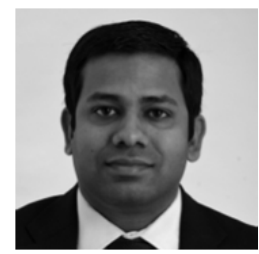

Kaushik Das (S'13-M'17) is currently a postdoctoral researcher at Department of Wind Energy in Technical University of Denmark. He finished his $\mathrm{PhD}$ from same department in 2016. He received M.Tech degree in power system engineering from the Indian Institute of Technology Kharagpur, India in 2011. Previously, he was working with IBM Research in smart grid research. His current research interests include integration and control of renewables, weather dependency of power systems and power system defence plans.

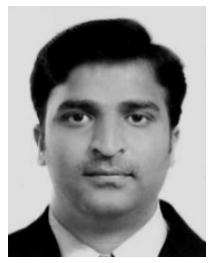

Jayachandra N. Sakamuri (M'15) was born in 1982 and received the $\mathrm{M}$.Tech degree in electrical engineering at the Indian Institute of Technology, Kanpur, India in 2009. He also worked on his M.Tech thesis at Technical University of Berlin, Germany during 2008. He completed his $\mathrm{PhD}$ in coordinated control of wind power plants connected in offshore HVDC Grid. At present, he is working as R\&D Engineer at ABB HVDC. 